\title{
Personal Financial Behavior: The Influence of Quantitative Literacy and Material Values
}

\author{
Pete Nye \\ University of Washington Bothell, pnye@uwb.edu \\ Cinnamon Hillyard \\ University of Washington Bothell, chillyard@uwb.edu
}

Follow this and additional works at: https://digitalcommons.usf.edu/numeracy

Part of the Curriculum and Social Inquiry Commons, Finance and Financial Management Commons, Organizational Behavior and Theory Commons, and the Science and Mathematics Education Commons

\section{Recommended Citation}

Nye, Pete, and Cinnamon Hillyard. "Personal Financial Behavior: The Influence of Quantitative Literacy and Material Values." Numeracy 6, Iss. 1 (2013): Article 3. DOI: http://dx.doi.org/10.5038/1936-4660.6.1.3 


\title{
Personal Financial Behavior: The Influence of Quantitative Literacy and Material Values
}

\begin{abstract}
Some consumers finance discretionary spending at extremely high interest rates. Many carry substantial balances on their credit cards at effective annual rates as high as 36 percent, and some pay annual rates on "pay day" loans as high as 400 percent. High interest debt can rapidly cascade into an overwhelming financial burden, threatening the consumer's credit and long-term financial health.

This survey study investigates how quantitative literacy may promote forward-looking financial decisions, decisions that recognize the long-term consequences of current choices and may favor the future over the present. In addition, we examine the consumer's confidence in their quantitative skills. Confidence in working with numbers could help consumers think through the implications of their financing choices. Although quantitative literacy and consumer education matter, we propose that consumer values also may be important in explaining financial behavior. In particular, materialism may drive many American consumers to take on high levels of debt. Understanding consumer financing choices may require a better understanding of the consumption behavior that motivates those choices.

Results from a diverse sample $(n=267)$ of consumers confirm that both quantitative literacy and subjective numeracy, the individual's confidence in applying quantitative skills, are positively related to forward-looking financial behavior. The impact of materialism on financial behavior is largely mediated by impulsive consumption, the tendency to make frequent purchases without forethought or consideration of the financial consequences. Finally, subjective numeracy may encourage a less-impulsive, moreconsidered approach to consumption decisions.
\end{abstract}

\section{Keywords}

financial decision-making, financial quantitative literacy

\section{Creative Commons License}

\section{c) (7) (8)}

This work is licensed under a Creative Commons Attribution-Noncommercial 4.0 License

\section{Cover Page Footnote}

Pete Nye, an Associate Professor of Marketing, is a founding faculty member in the Business School at the University of Washington Bothell. He teaches statistics, negotiations, consumer psychology and personal finance. His research examines decision making, conflict management, and biases in judgment.

Cinnamon Hillyard, an Associate Professor of Mathematics, is a faculty member in the School of Interdisciplinary Arts and Sciences at the University of Washington Bothell. She is a past Chair of the SIGMAA-QL and past Secretary-Treasurer of the NNN. She is currently directing the Quantway project at the Carnegie Foundation for the Advancement of Teaching. She teaches mathematics, statistics, and interdisciplinary research and writing courses. Her research focuses on the assessment of quantitative literacy and on how adults use quantitative literacy to make decisions. 


\section{Introduction}

Some consumers finance discretionary spending at extremely high interest rates. Many carry substantial balances on their credit cards at effective annual interest rates as high as 36 percent, whereas others pay annual rates on "pay day" loans as high as 400 percent (Stegman 2007). High interest debt can rapidly cascade into an overwhelming financial burden, threatening the consumer's credit and longterm financial health. Yet seemingly thoughtful consumers often make financial choices that bring costly long-term consequences. These choices are so widespread that recent federal legislation (the Credit Card Responsibility, Accountability and Disclosure $\mathrm{Act}^{1}$ ) requires credit card companies to bring this potential danger to the attention of their cardholders. Why do some consumers engage in this behavior, whereas others make financial choices that promote longterm financial health?

We propose that financial behavior is difficult to understand, partly because its causes are complex. This study examines three hypothesized correlates of financial behavior and the related affective state, an individual's sense of financial well-being. Although we emphasize the positive role of quantitative literacy, we propose that two dispositional factors also may be important in explaining financial behavior: 1) the consumer's confidence in his/her ability to use quantitative skills to support decisions (subjective numeracy), and 2) the extent to which the consumer relies on the consumption of goods as a source of happiness and personal gratification (materialism). Before proceeding, we will briefly clarify the importance of these three factors: quantitative literacy, subjective numeracy and materialism.

\section{Quantitative Literacy and Subjective Numeracy}

Considerable previous research (Huston 2010; Lusardi and Mitchell 2007; Gilliland et al. 2011) suggests that quantitative literacy encourages informed financial choices. Consumers may make decisions that downplay long-term outcomes, because they do not understand financing alternatives or they have difficulty with basic quantitative tools. For example, a consumer who does not understand how interest compounds might underestimate the burden of credit card financing. To the extent that such choices are caused by a lack of quantitative and financial knowledge, consumer decisions could be improved through thoughtful educational programs. Many such programs have been developed by government agencies, educational institutions, and consumer groups.

\footnotetext{
${ }^{1}$ http://www.gpo.gov/fdsys/pkg/PLAW-111publ24/pdf/PLAW-111publ24.pdf (accessed Nov. 12, 2012)
} 
Do consumers carefully examine the financial implications of their choices? For example, do they mobilize their quantitative abilities when making borrowing decisions, or do they avoid this cognitive effort? This is an issue of disposition rather than ability. Even quantitatively able consumers may fail to think through the long-term implications of their spending and financing choices. When consumers have the confidence and inclination to leverage their quantitative skills, they may better understand both the present and future costs and benefits of their financial decisions. Subjective numeracy may encourage them to "run the numbers," read the financing terms, and interpret the brochures.

\section{Materialism}

Understanding financing choices may require an appreciation of the consumption behavior that necessitates that financing. For some Americans, discretionary consumption is central to their sense of self-worth, and pleasure shopping is a frequent recreational activity (Schor 1998, p. 158). Materialism may drive consumers to take on high levels of expensive debt. For example, when a consumer impulsively purchases a high-priced item with a credit card, she/he may be simultaneously making a financing decision without fully considering the longterm implications and without evaluating financing options.

The primary objective of this research is to better understand how quantitative literacy and dispositional factors affect both consumption behavior and financial choices. We hope to provide insights useful in designing educational initiatives to improve financial literacy and financial decisions.

\section{Literature Review}

\section{Financial Behavior and Personal Financial Well-being}

National statistics on financial choices of American consumers are alarming. The United States Court data ${ }^{2}$ reveal that 1.3 million bankruptcies were filed from March 2011 to March 2012. According to the Federal Reserve ${ }^{3}$, American's "revolving credit" debt (mostly credit cards) totaled over $\$ 852,000,000,000$ in August 2012. Although this is down from a high of over 1 trillion in 2008, this balance is an $11.2 \%$ increase from the 2011 balance. College students are also taking on large amounts of debt. According to the Project on Student Debt, ${ }^{4} 67 \%$

\footnotetext{
${ }^{2}$ http://www.uscourts.gov/statistics/bankruptcystatistics.aspx (accessed Nov. 15, 2012)

${ }^{3} \mathrm{http}: / /$ www.federalreserve.gov/releases/g19/HIST/cc_hist_sa_levels.html (accessed Nov. 19, 2012)

${ }^{4}$ http://projectonstudentdebt.org/ (accessed Nov. 12, 2012)
} 
of students graduating from college in 2011 had student loans with an average debt of $\$ 26,600$. A 2011 report from Sallie $\mathrm{Mae}^{5}$ cites that $87 \%$ of students have a credit card with an average balance of $\$ 800$ per month.

While financial decisions that favor the present over the future can directly affect the consumer's balance sheet, they can also inflict psychological damage. For this reason, we examine the impact of quantitative literacy on both financial behavior and on the consumer's resultant sense of financial well-being. Researchers have demonstrated that strained finances can threaten an individual's psychological well-being (Mirowsky and Ross 2003; Mills et al. 1992). Personal financial well-being has been associated with fewer reported health problems (Kim et al. 2003) and higher workplace productivity (Kim and Garman 2003). Prawitz et al. (2006a) argue that educational programs targeting financial literacy should attempt not only to change financial behaviors, but also to demonstrate measurable improvements in financial well-being.

\section{Quantitative Literacy and Subjective Numeracy}

Quantitative Literacy (QL) has been the focus of many recent calls for action in higher education. In particular, the American Association of Colleges and Universities (AAC\&U) calls for a citizenship with the "competency and comfort in working with numerical data." Further, "individuals with strong QL skills possess the ability to reason and solve quantitative problems from a wide array of authentic contexts and everyday life situations." Scholarship in QL has focused on multiple decision-making contexts including environmental studies, business, health decisions, and financial decisions. Three key studies on the importance of $\mathrm{QL}$ in decision-making are described below.

In the health sciences, the role of QL in decision-making has been widely studied. In a summary of the literature around QL and health decision-making, Lipkus and Peters (2009) reviewed evidence that a higher level of QL leads to better health choices. Specifically, they identify six "functions" of numeracy in medical decision-making that previous research has documented: (1) People with higher numeracy are more likely to do simple counts, compare the magnitude of numbers, and perform arithmetic operations with less error. (2) People with higher numeracy are more likely to seek out and pay attention to numerical information presented to them in the decision-making process. (3) Numerate people are more likely to correctly interpret and evaluate numbers provided to them. (4) Increased numeracy leads to better probability assessment. (5) Numerate people are more likely to think critically about the data presented to

\footnotetext{
${ }^{5}$ https://www1.salliemae.com/about/news_info/research/how_america_pays_2011/ (accessed Nov. 12, 2012).

${ }^{6}$ AAC\&U QL Value Rubric, www.aacu.org/value/rubrics/pdf/QuantitativeLiteracy.pdf (accessed Nov. 12, 2012).
} 
them, accepting it when it is reasonable and discarding it when it does not make sense. (6) Numeracy promotes behavioral change. Although some of the studies cited are limited to the context of health decisions, the same results might be seen in other decision-making contexts.

Quantitative literacy has also been linked to financial decision-making. Gilliland et al. (2011) surveyed college freshman to assess the relationship between financial literacy, quantitative literacy, ACT mathematics scores, and demographic variables. They found a large positive relationship between quantitative literacy and financial literacy. In another study, Cokely and Kelley (2009) found that higher levels of quantitative reasoning resulted in better decisions involving risk, specifically lotteries and gambling. They found that "People higher in working memory span, cognitive reflectiveness, and those with greater skill in comprehending and transforming probabilities often made choices consistent with expected value" (p. 29). Working with the Rand American Life Panel dataset, Lusardi and Mitchell (2007) provided evidence that quantitative financial literacy is important in retirement planning. They measured financial literacy as a combination of quantitative literacy (e.g., percentage change, compound interest, time value of money, and doubling) and institutional knowledge (e.g., knowledge of stock markets, money market accounts, interest rates, and bonds).

While these studies demonstrate the importance of QL in promoting decisionmaking and behavioral change, they also suggest that being able to "run the numbers" is not enough. A willingness to use numeracy skills at the time of decision-making is also important. For example, Cokely and Kelly (2009) utilize a Cognitive Reflection Test (CRT) "which assesses differences in cognitive impulsivity ... versus more deliberative thinking" (p. 23) to demonstrate this distinction. The importance of both "competency and comfort" is also reflected in AAC\&U's definition of QL. Lipkus and Peters (2009) note that numeracy leads to a willingness to critically think about the numbers being presented.

Fagerlin et al. (2007) developed a scale to measure subjective numeracy. Instead of asking subjects to compute answers to questions, this scale asks them to rate their level of experience, interest, ability, and preference with numerical tasks. Although this scale is correlated with numerical skills $(r=0.53)$, it appears to be measuring something more than ability alone.

We hypothesize that persons with greater quantitative literacy skills will make more forward-looking financial choices. We also hypothesize that persons with higher "subjective numeracy" will make more forward-looking choices. That is, a preference for working with numbers and the confidence to do so can help. Skills alone are not sufficient. 


\section{Materialism and Consumer Spending}

Materialism. Understanding consumer financing choices may require a better understanding of the consumption behavior that necessitates those choices. Materialism may drive many Americans to consume in excess and to take on debt to support that consumption. Belk (1984, p. 291) defines materialism as "the importance a consumer attaches to worldly possessions." Richins (2004, p. 210) describes materialism this way: "The importance ascribed to the ownership and acquisition of material goods in achieving major life goals and desired states." Richins and Dawson (1992) view materialism as an important value that drives behavior and life decisions. Materialistic people place more value on material possessions and less emphasis on interpersonal relationships than do people who are less materialistic (Richins 1994). They organize their lives around acquiring possessions (Richins and Dawson, 1992, p. 307). Social critics have observed that American society is highly materialistic relative to some other developed economies (Barber 2007; James 2008) and that consumer debt is more common in the United States than elsewhere. For some Americans, discretionary consumption is central to their sense of self-worth, and pleasure shopping is a frequent recreational activity (Schor 1998, p. 158).

Impulsive Consumption. Previous research suggests a strong association between materialism and impulsive buying (Cole and Sherrell, 1995). Individuals who rely heavily on the consumption of goods as a source of happiness and personal gratification may be more inclined to make unplanned or impulsive purchases without fully considering the financial implications. For example, economist Juliet Schor describes the prevalence of "retail therapy":

Millions of Americans use consuming as a way to fight the blues, to savor a happy moment, to reward themselves, to enhance self-esteem, or to escape from boredom. Indeed, consumerism is so persuasive that "retail therapy" is a response to just about any mood state or psychological problem (1998, p.158).

In the extreme, this behavior has been identified as a psychological disorder, a form of addiction often called compulsive consumption. Compulsive buyers seem unable to control their strong desire to spend, even when the behavior is clearly disruptive to their lives, relationships and financial well-being. They often try to hide their behaviors and fail to acknowledge the damaging consequences. "Interviews conducted with compulsive consumers typically contain accounts of shopping sprees in which they describe themselves as being completely 'out of control,' buying things they didn't need and sometimes couldn't even use" (Faber et al. 1987, p. 133). Studies estimate that compulsive buying afflicts between 2 and 16 percent of American adults; a large-sample study in 2006 estimated that 5.8 percent suffer from this disorder (Koran et al., 2006, p. 1806). 
Impulsive buying, a less disruptive form of problem consumption, is far more common and is not viewed as a psychological disorder. Thomas Hine describes its prevalence:

The most troubling thing about the literature on problem shopping is how closely it seems to resemble behavior and feelings that most shoppers would consider normal. One study argues that addictive shoppers are driven by the fear of missing out, just as most other shoppers are. ... Still, everyone who has ever gone shopping has sometimes come home, looked at a purchase, and wondered, "What was I thinking?" In retrospect, it often seems that you weren't thinking at all, that you were simply caught up in a mania of acquisition (2002, p. 8).

Schor (1998, p. 159) notes that although clinical compulsives represent the extreme case, "Millions of ordinary people also exhibit high 'generalized urges to buy.' Indeed, an innocuous form of compulsive buying appears to afflict onequarter of us." However, to the extent that impulsive consumers finance with credit cards, forego savings and damage their credit ratings, this proclivity is not innocuous. It is financially costly and can be a source of stress.

Since impulsive consumption is an urge rather than an addiction, motivated consumers may be able to exert some control. In her 1998 study, The Overspent American, Schor argues that consumers should not only be comfortable running the numbers when making financing decisions, but they should also be prepared to do so at the point of purchase. After all, when a major purchase is made, the financing is often determined. She raises the hope that through educational programs, consumers can perhaps learn to discipline their spending:

We must also teach our kids to be savvy consumers, forewarning them especially about the risks of credit cards. They must know that when they buy on credit, they may end up paying two, three or four times the sticker price. They need to be able to figure out, in the store, how much more. (Schor 1998, p. 158)

Consistent with Schor's suggestion, some of our students report being quite materialistic, but still disciplined in their spending. Although they place a high value on material goals, they recognize that to achieve these goals, they must stretch their dollar. Hence, they are motivated to apply their analytical tools. Understanding the opportunity costs of undisciplined spending motivates them to resist impulse purchases and "feel good" shopping sprees. They often shop with a calculator. We call these consumers instrumental materialists, as distinguished from impulsive materialists. Although we have no prior evidence on this point, greater subjective numeracy may help consumers to resist impulse spending.

We hypothesize that highly materialistic consumers will engage in less forward-looking financial behavior than will less-materialistic consumers. Further, the impact of materialism on financial behavior will be partially mediated by impulsive/unplanned consumption. That is, highly materialistic consumers are more inclined to spend impulsively. To support this consumption they may take 
on high interest debt. Finally, we predict that subjective numeracy may be negatively related to impulsive consumption.

\section{The Model and Hypotheses}

Our model (Figure 1) attempts to identify consumer characteristics that influence two important outcomes: financial behavior and personal financial well-being, the affective state that may accompany forward-looking behavior. As with many behavioral models, the proposed direction of causation runs from individual differences to behavior to affective state. Huston (2010, p. 308) in her metaanalysis of financial literacy research recommends a similar approach for modeling financial well-being: financial literacy (and other "human capital" factors $) \rightarrow$ financial behavior $\rightarrow$ financial well-being.

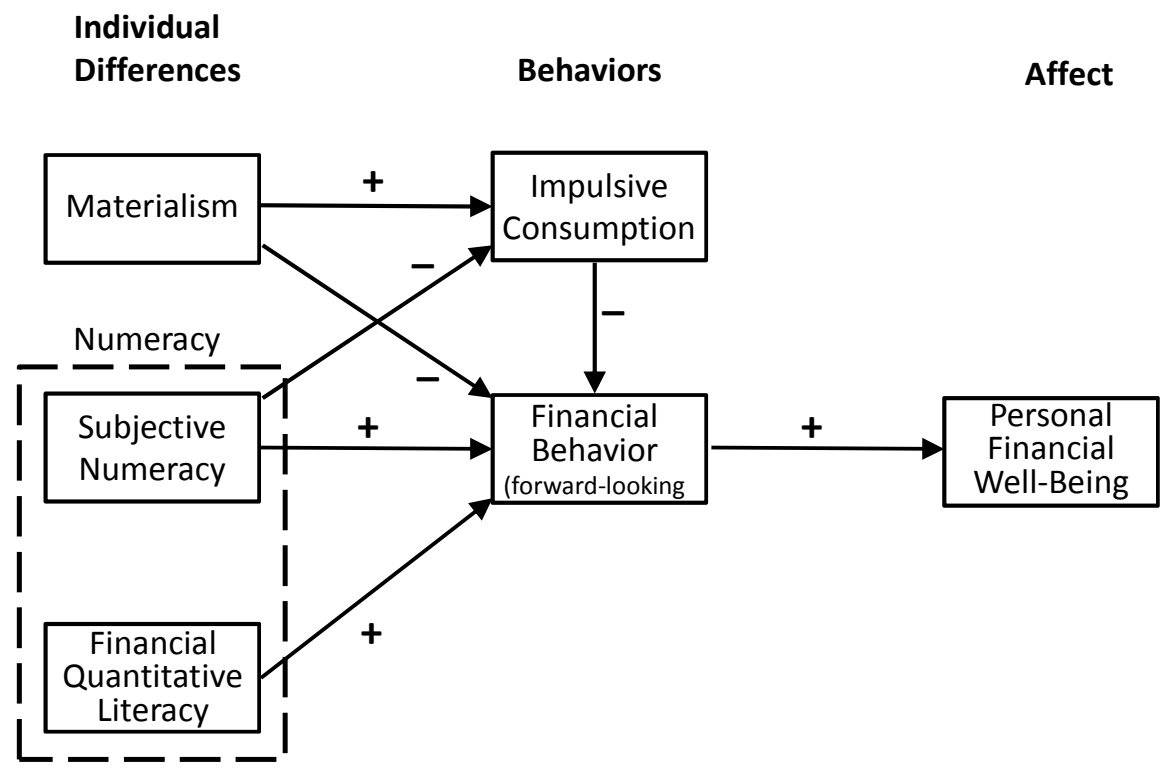

Figure 1. Proposed Path Model: Impact of materialism, subjective numeracy and quantitative literacy on financial behavior.

We propose that quantitative literacy will be positively related to forwardlooking financial behavior and a sense of financial well-being, whereas materialism will be negatively related to these outcomes. However, our model captures two important refinements. First, we propose that financial quantitative literacy, a measure of objective understanding, and subjective numeracy, a measure that captures an individual's preference for using numbers, both help to explain financial behavior. Second, we propose that materialism influences financial behavior partly through the mediating variable, impulsive consumption. Below, we state our six hypotheses. 
Two hypotheses capture the expected effect of materialism on financial behavior:

H1: Consumers scoring higher on materialism will engage in less forwardlooking financial behavior. That is, they will tend to make decisions that favor present benefits over future benefits.

$\mathrm{H} 2$ : The impact of materialism on financial behavior is partially mediated by impulsive consumption. That is, highly materialistic consumers will be more inclined to engage in impulsive, unplanned consumption. To support this consumption, consumers will make financial choices that favor present benefits over future benefits.

Four hypotheses capture the expected effect of quantitative literacy on financial behavior:

H3: Consumers demonstrating greater financial quantitative literacy will (a) engage in more forward-looking financial behavior and (b) report a greater sense of personal financial well-being.

H4: Consumers reporting greater subjective numeracy will (a) engage in more forward-looking financial behavior and (b) report a greater sense of personal financial well-being.

H5: Financial quantitative literacy and subjective numeracy, although correlated, both help to explain financial behavior. Subjective numeracy is a distinct construct that contributes uniquely to our understanding of financial behavior.

H6: Consumers scoring higher on subjective numeracy will be less impulsive in their consumption behaviors.

Hypothesis 5 emphasizes the critical importance of subjective numeracy, the consumer's confidence in his/her quantitative abilities and preference for using numbers when making decisions. Disposition matters. Even quantitatively astute consumers may resist examining the numbers at the point of decision. Without leveraging their quantitative skills, they too may fail to appreciate the long-term costs of current choices. Finally, subjective numeracy may provide an additional benefit. It may constrain impulsive consumption by influencing consumer decisions at the point of purchase (H6).

\section{Method}

Our model (Fig. 1) can be represented by three equations, one explaining each endogenous variable. We used ordinary least squares regression to estimate these 
equations. Estimating the model required measures of three explanatory variables (materialism, financial quantitative literacy and subjective numeracy), two behavioral outcomes (impulsive consumption and prudent financial behavior), and one affective outcome (personal financial well-being).

We developed an 18-page survey to measure these variables and basic demographic characteristics. We administered the survey to 267 subjects (ages 18 to 67) at multiple public locations (throughout the Northern Puget Sound area) including career centers, community libraries, PTA events, and college lobbies. A grant from our institution's Teaching and Scholarship Enhancement Project provided funding to pay each participant $\$ 20$, and our Institutional Review Board approved our research. Participants completed the instrument in a single session and entirely

Table 1

Sample: Demographics

\begin{tabular}{lcc}
\hline $\begin{array}{l}\text { Sample Size } \\
\text { Female }\end{array}$ & & 267 \\
Age & Mean & $47 \%$ \\
& $<21 \mathrm{yrs}$ & 35 \\
& 21 to 35 & $50 \%$ \\
& 36 to 50 & $27 \%$ \\
& $>50 \mathrm{yrs}$ & $14 \%$ \\
Education & & \\
\multicolumn{2}{c}{ High school grad } & $89 \%$ \\
\multicolumn{2}{c}{ College grad } & $61 \%$ \\
\hline
\end{tabular}
on their own. Pens, scratch paper, and calculators were available. No time limits were imposed, and most participants were very diligent. The mean completion time was 37 minutes ( $s d=13$ minutes). Nine surveys were dropped because respondents chose not to finish the study or provided insufficient information to measure key variables. Table 1 summarizes the demographics of our sample. The majority of our sample had a college diploma and was in the working/wealthbuilding age range (21 to 50 years).

\section{Outcome Variables}

Financial Behavior. To measure the key outcome variable, financial behavior, participants reported how regularly they engage in fifteen specific behaviors, using a five-point scale ( $1=$ never, $5=$ frequently) (see Appendix A). Some of these behaviors focus on future benefits (e.g., saving for unexpected expenses), and others focus on present benefits (e.g., taking cash advances on credit cards to finance current consumption). The financial behavior score describes the consumer's behavior on a continuum from present-focused to future-focused. Higher scores indicate more future-focused or forward-looking financial choices. In an exploratory factor analysis, the fifteen items load on four dimensions of financial behavior: consumer borrowing, credit card financing, saving/budgeting and investing. In this study we use the single higher-order factor score.

As this scale is in development and needs refinement, its psychometric properties are not well established. However, the scale items (Appendix A) capture a range of financial behaviors focused on either present benefits or future 
benefits (content validity). In addition, this study provides initial evidence of construct validity. As theory and intuition would suggest, forward-looking financial behavior is positively correlated with a sense of personal financial wellbeing $(r=0.69)$ and negatively correlated with impulsive consumption $(r=-0.44)$.

Personal Financial Well-being. To measure the affective outcome, a sense of financial well-being, participants responded to the InCharge Financial Distress/Financial Well-Being Scale (Prawitz et al. 2006a), hereafter referred to as Financial Well-Being. This scale treats financial stress and financial well-being as two ends of a continuum, ranging from overwhelming financial distress (1) to highest financial well-being (10). The Financial Well-Being score is an average response to four questions about the consumer's financial situation and four questions about their subjective sense of financial well-being. Factor analysis of our data confirms that the eight items load on a single factor with high internal reliability (Cronbach's alpha $=0.956$ ). In addition, large-sample studies with this scale establish strong construct validity and predictive validity (Prawitz et al. 2006b). For our sample, the mean and standard deviation of the Financial Wellbeing scale are 5.43 and 2.39 , respectively.

\section{Explanatory Variables}

Financial Quantitative Literacy. To measure competency in financial quantitative literacy, we developed a 13-item test of skills (Appendix B). These items test the ability to use key QL skills including percentages, unit conversions, rates, and the time value of money; they also require respondents to interpret tables and graphs. These skills were tested in financial contexts such as budgeting, calculating sales tax, making currency conversions, and calculating interest on investments and loans. Although the mathematical computations were minimal (e.g., addition, subtraction, multiplication, ratios), the questions were contextual so that respondents needed to determine which operation to perform in order to get the correct answer.

For our sample, the mean score on the

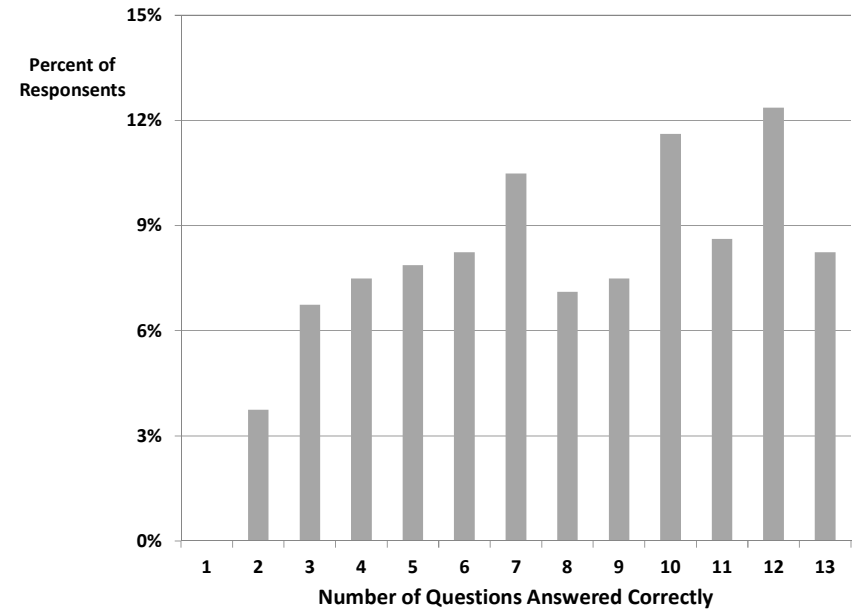

Figure 2. Financial QL: Distribution of scores financial quantitative literacy assessment was 62 (\% correct) with a standard deviation of 25. As seen in Figure 2, scores are widely distributed indicating that 
our subjects exhibited a diverse range of mastery of these skills. This also indicates that our scale is a discriminating measure. Note that approximately half of our respondents scored lower than 60 percent on this test of essential quantitative skills. This finding is consistent with the results reported by Gilliland et al (2011).

Although this measure is new and not fully validated, the current study provides promising evidence of construct validity. Like objective measures of medical numeracy, it is moderately correlated with subjective numeracy $(r=$ $0.483)$. Further, as expected, the average score increases with education. Subjects with no college $(\bar{x}=0.455)$ score lower than those with a college degree $(\bar{x}=0.748)$. Finally, the average scores for male $(\bar{x}=0.612)$ and female $(\bar{x}=0.601)$ subjects are equal.

Subjective Numeracy. In addition to measuring quantitative abilities objectively, we used the Subjective Numeracy Scale (SNS) created by Fagerlin et al. (2007). This scale was validated by Zikmund-Fisher et al. (2007). This eight-item scale measures people's perceptions of their numerical skills (e.g., "How good are you at working with fractions?") as well as their preferences regarding the presentation of numerical information (e.g., "How often do you find numerical information to be useful?"). Multiple studies have used this scale to measure how people's experience, interest, and ability with numerical tasks affect their decision-making about health issues. Scores range from 1 (lowest) to 6 (highest) confidence and preference. Although this scale is often used as a replacement for an objective numeracy scale, we explore its ability to measure a different aspect of quantitative literacy that moves beyond being able to do the computations. For our sample, the mean and standard deviation of the subjective numeracy scale are 4.41 and 1.01, respectively.

Materialism. The 15-item Material Values Scale (MVS) measures "the importance ascribed to the ownership and acquisition of material goods in achieving major life goals." This scale has high internal consistency, with Cronbach's alpha ranging from 0.79 to 0.91 (Richins 2004). The MVS includes three correlated subscales: "the use of possessions to judge the success of others and oneself," "the centrality of possessions in a person's life," and "the belief that possessions and their acquisition lead to happiness" (Richins 2004, p. 210). However, few published studies examine the subscales. We use the more robust 15-item instrument in this study. Subjects responded to the 15 statements using a seven-point Likert scale. In this paper, scores on the Material Values Scale (MVS) are an average of these responses $(1=$ low materialism, $7=$ high materialism). For our sample, the mean and standard deviation of the materialism scale are 3.65 and .98 , respectively. 
Impulsive Consumption. To assess impulsive/unplanned consumption, participants completed the Diagnostic Tool for Classifying Compulsive Consumers (Faber and O'Guinn 1989). Using five-point Likert scales, subjects indicate how well 14 statements describe their behavior. The compulsive consumption score, ranging from 14 to 70 , is the sum of the 14 responses. Normally, low scores indicate high compulsivity. However, we reverse-scored the items such that higher scores indicate more impulsive behavior. The 14 items load on a single interpretable factor with moderate internal reliability (Cronbach's alpha $=.83$ ). For our sample, the mean and standard deviation of the compulsive consumption scale are 30.80 and 9.57 , respectively.

The scale was designed to identify compulsive buying, viewed by the authors as an addictive behavior that can threaten financial health, relationships and normal functioning. Although the scale effectively identifies compulsives (a small portion of consumers with extreme scores), we use it for a slightly different purpose, to identify any tendency towards impulsive/unplanned consumption. Some of the 14 statements clearly describe extreme behavior (e.g., "I went on a buying binge and wasn't able to stop"); but others capture a more moderate tendency towards impulsive consumption (e.g., "I have bought something in order to make myself feel better"). Cole and Sherrell (1995) in their analysis of compulsive buying measures confirm that the scale can effectively distinguish among three groups: normal buyers, impulsive buyers and compulsive buyers. Although not engaging in addictive behavior, impulsive buyers may make frequent unplanned purchases to boost mood or reduce anxiety, and they may buy items that they cannot afford.

\section{Results}

\section{The Estimated Model}

We tested the proposed model (Figure 1) by estimating three regression equations, one for each endogenous variable. Table 2 presents the three equations using standardized regression coefficients, and Figure 3 summarizes the collective results. Figure 3 reports all significant path coefficients. Absolute values close to 0.3 suggest medium effects. Values less than 0.10 indicate weak effects, and values greater than 0.5 indicate large effects (Kline 1998, p. 149). Figure 3 differs from the hypothesized model (Fig. 1) in three respects. First, the direct path from materialism to financial behavior has been dropped, as the relationship was not significant. Second, financial quantitative literacy is directly related to Personal Financial Well-being. Third, we report a weak path from impulsive consumption to Personal Financial Well-being. These modifications were empirically driven. 
Table 2

Estimated Model: Three regression equations

\begin{tabular}{|c|c|c|c|c|c|c|c|}
\hline \multirow[b]{2}{*}{ Model } & \multirow[b]{2}{*}{ Dependent Variable } & \multicolumn{5}{|c|}{ Independent Variables } & \multirow[b]{2}{*}{$\mathrm{R}^{2}$} \\
\hline & & Materialism & $\begin{array}{l}\text { Subjective } \\
\text { Numeracy }\end{array}$ & $\begin{array}{c}\text { Financial } \\
\text { Quantitative } \\
\text { Literacy }\end{array}$ & $\begin{array}{c}\text { Implusive } \\
\text { Consumption }\end{array}$ & $\begin{array}{l}\text { Financial } \\
\text { Behavior }\end{array}$ & \\
\hline 1 & Impulsive Consumption & $.343(.001)$ & $-.224(.001)$ & & & & .19 \\
\hline 2 & Financial Behavior & & $.245(.001)$ & $.191(.001)$ & $-.322(.001)$ & & .32 \\
\hline 3 & Personal Financial Well-being & & & $.128(.008)$ & $-.100(.041)$ & $.597(.001)$ & .50 \\
\hline
\end{tabular}

Note. Table reports standardized regression coefficients with $p$-values (2-tailed) in parentheses.

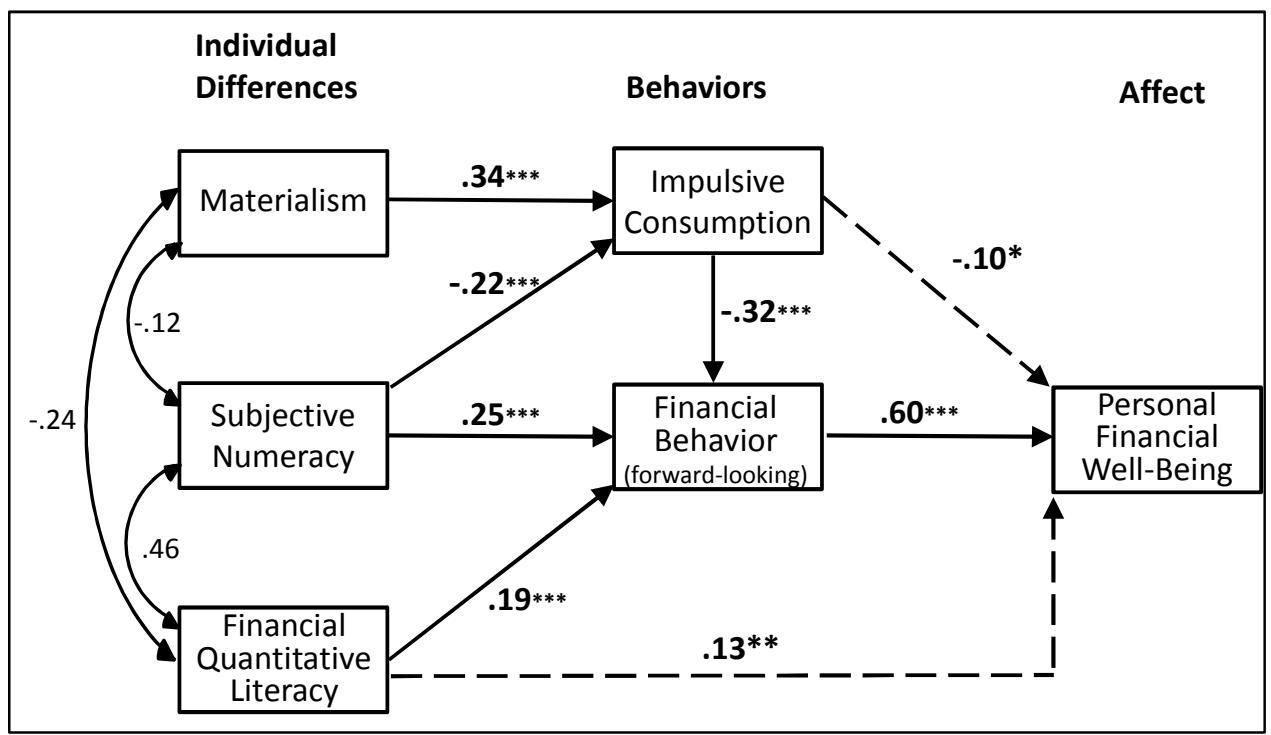

Figure 3. Estimated Path Model. Standardized regression coefficients are shown for all significant paths: $* p<.05, * * p<.01, * * * p<.001$. Dotted lines represent paths that were not hypotheisized.

\section{The Influence of Materialism and Impulsive Consumption}

Materialism is negatively related to forward-looking financial behavior. The bivariate correlation (Table 3 ) between the two variables supports hypothesis 1 ( $r$ $=-0.261, p<0.001)$. However, we also proposed that materialism is related to financial behavior partly through the mediating variable, impulsive consumption. 
Table 3

Bivariate Correlations Between Model Variables

\begin{tabular}{llccccc}
\hline & & 1 & 2 & 3 & 4 & 5 \\
\hline 1 & Materialism & & & & & \\
2 & Subjective Numeracy & $-.122^{*}$ & & & & \\
3 & Financial Quantitative Literacy & -.244 & .461 & & & \\
4 & Impulsive Consumption & .371 & -.267 & -.264 & & \\
5 & Financial Behavior & -.261 & .415 & .385 & -.438 & \\
6 & Personal Financial Well-being & -.280 & .381 & .386 & -.395 & .690 \\
\hline
\end{tabular}

Note: $*=$ significant at .05 . All other correlations are significant at .001 .

Table 4

Mediation Test: Impulsive consumption mediates the relationship between materialism and financial behavior

\begin{tabular}{clcc}
\hline & & \multicolumn{2}{c}{ Independent \& Mediator Variables } \\
\cline { 3 - 4 } Model & Dependent Variable & Materialism & $\begin{array}{c}\text { Impulsive } \\
\text { Consumption }\end{array}$ \\
\hline 1 & Financial Behavior & -.261 & -.438 \\
2 & Financial Behavior & & \\
3 & Impulsive Consumption & .371 & -.396 \\
4 & Financial Behavior & $-.114 \mathrm{~ns}$ & \\
\hline $\begin{array}{l}\text { Note. Table reports standardized regression coefficients. } \\
\text { All other coefficents are significant at .001. }\end{array}$
\end{tabular}

To test this mediation effect, we use the regression procedure recommended by Baron and Kenney (1986). We estimate three regression models. First, we establish that the independent variable is related to the dependent variable (materialism $\rightarrow$ financial behavior). Second, we establish that the independent variable is related to the proposed mediator (materialism $\rightarrow$ impulsive consumption). Finally, we regress the dependent variable (financial behavior) on both the independent variable (materialism) and the proposed mediator (impulsive consumption). If the coefficient of the mediator is significant, while the coefficient of the independent variable becomes non-significant, we conclude that the relationship between the independent variable and the dependent variable is fully mediated. If the mediator is significant while the independent variable becomes less significant, we conclude that the impact of the independent variable 
is partially mediated. This test is presented in Table 4 . Note that materialism is negatively related to forward-looking financial behavior (model $1, p<.001$ ). Second, materialism is positively associated with impulsive consumption (model $3, p<.001)$. Finally, Model 4 regresses financial behavior on both materialism and impulsive consumption. Materialism becomes non-significant, while impulsive consumption remains highly significant. Consistent with hypothesis 2 , the relationship between materialism and financial behavior appears to be substantially mediated by impulsive consumption. Although mediation cannot be proven with non-experimental data, these results suggest that the mediation hypothesis is plausible.

\section{The Influence of Quantitative Literacy and Subjective Numeracy}

Financial quantitative literacy is positively correlated with both financial behavior and personal financial well-being (Table 3). This confirms hypotheses $3 \mathrm{a}$ and $3 \mathrm{~b}$. Similarly, subjective numeracy is positively correlated with both of these outcomes, confirming hypotheses $4 \mathrm{a}$ and $4 \mathrm{~b}$.

More interesting, hypothesis 5 proposes that quantitative literacy and subjective numeracy, although closely related constructs, each contribute uniquely to explaining financial behavior. Controlling for other variables specified in the model (Fig. 3), quantitative literacy and subjective numeracy each help to explain financial behavior, as indicated by their significant path coefficients $(0.19$ and 0.25 , respectively). Quantitative literacy appears to be linked to financial wellbeing, the affective state, both directly and indirectly through its association with financial behavior.

Finally, subjective numeracy is directly related to consumption decisions, as well as financing decisions. This is indicated by the path coefficient (Fig. 3) from subjective numeracy to impulsive consumption (coeff $=-0.22, p<0.001$ ). Consumers who are more comfortable "running the numbers" may be less impulsive in their consumption behaviors. This result requires further investigation and replication. Collectively, these findings highlight the usefulness of subjective numeracy in efforts to understand and influence financial behavior. The confidence to think through decisions and apply quantitative insights may be as important as the ability to do so.

\section{Concluding Remarks}

Thoughtful consumers often make seemingly shortsighted financial choices. This behavior is difficult to understand partly because its causes are complex. Examining a broad sample of American consumers, we identified three important correlates of forward-looking financial behavior. First, this study confirms that 
more quantitatively literate consumers make more forward-looking financial choices. Second, subjective numeracy, the confidence and preference to apply quantitative tools during the decision process, is associated with forward-looking financial behavior. Consumers should be both able and willing to work the numbers. Finally, some costly financial decisions may be driven by impulsive consumption, common among materialistic consumers. Because this unplanned consumption is not carefully thought through, it may be done in ignorance of the financial consequences.

\title{
Implications for Financial Literacy Education
}

As these findings are based on correlational data, they are tentative and require further investigation. However, collectively they highlight the need for creative initiatives in financial education. In her study of the spending and borrowing habits of American consumers, Schor drew attention to this need:

\begin{abstract}
Americans also need to learn how not to spend - how to budget, plan their finances, be patient, and save. Most American households don't have a family budget, and those who do tend not to follow them. ... Financial management is neglected by the U.S. education system. ... In addition to straightforward material such as the economics of compound interest and how to evaluate the long-term consequences of different savings patterns, young people also need to be taught about basic monthly expenses, how to make and stick to a budget, how to calculate what it takes to rent an apartment, and the true costs of owning a car. (1998, p. 157)
\end{abstract}

The current study reinforces this concern and suggests some promising directions for pedagogical exploration.

Motivation matters. Educational initiatives could cultivate student confidence in their abilities to apply quantitative tools when making important personal decisions. In this study, subjective numeracy helped to explain both financial and consumption behaviors. This finding supports efforts to teach QL in the context of personally relevant decisions. Students need to be confident that they can "run the numbers" and interpret quantitative information when making financial decisions. Embracing QL as a decision-making tool could help them achieve their personal goals.

Material values (and attitudes towards consumption) also help to explain financial behavior. Educational efforts could encourage students to explore their personal values and the consumption behaviors that influence their financial decisions. For example, consumers who make impulsive purchases for short-term gratification may be accumulating credit card debt that will be difficult to pay off. Similarly, our students often report purchasing automobiles on impulse, having visited the dealership merely to browse. To some extent, important financial choices may be driven by impulsive spending. If consumers understood the true costs of some unplanned purchases, they might exercise more constraint. In 
addition, it may be possible to train consumers to invoke their analytical tools earlier in the purchase decision process.

Financial decisions that downplay long-term costs and benefits can create stress and related health problems and can damage psychological well-being (Kim et al. 2003; Mirowsky and Ross 2003; Mills et al. 1992). Although behavior is the primary focus of this study, these affective outcomes must be examined to appreciate the far-reaching consequences of financial choices. In the current study, financial behavior strongly and directly influences personal financial wellbeing. Educational programs could incorporate interesting findings about the psychological and interpersonal impact of financial choices. This effort could include administering the Financial Stress/Financial Well-Being Scale (Prawitz et al. 2006a) to encourage student introspection. A better understanding of these psychological costs might motivate students to adopt a more cognitive and forward-looking approach to consumption and financing choices.

\section{Future Research}

Financial Quantitative Literacy vs. Financial Institutional Literacy. Financial literacy includes both the ability to apply quantitative reasoning to financial decisions and general knowledge about financial markets, instruments and institutions. This study examines only the former, what we call financial quantitative literacy. A more complete model of financial behavior would examine the impact of financial institutional literacy as well. A number of instruments that assess financial literacy emphasize institutional knowledge rather than quantitative understanding. This suggests two promising research directions. First, financial literacy is a complex construct, and a more comprehensive measure is needed. Huston (2010) provides a framework for developing a more complete standardized measure of financial literacy. She suggests that a measure should capture at least four knowledge domains: personal finance basics (i.e., time value of money, account concepts), borrowing, saving/investing and protection. Huston emphasizes that financial literacy requires more than factual knowledge:

... an individual must have the ability and confidence to use his/her financial knowledge to make financial decisions. When developing an instrument to measure financial literacy, it would be important to determine not only if a person knows the information but also if he/she can apply it appropriately. (2010, p. 307)

Second, financial quantitative literacy and financial institutional literacy may both promote better decision-making. Research could explore the relative impact of each on financial behavior.

Instrumental vs. Impulsive Materialism. These results suggest that, on average, higher levels of materialism are associated with more impulsive consumption and 
less forward-looking financial behavior. However, this conclusion may oversimplify the impact of materialism, a complex construct, on financial behavior. The role of materialism should be examined in a more nuanced fashion. For example, for some consumers, placing a high value on material acquisitions could motivate more forward-looking financial choices. A practical consumer may recognize that careful money management (saving, investing wisely, budgeting for consumption) can provide greater access to material goods in the long run. In the current study some participants who scored high on materialism also reported meticulous money management practices. Possibly, educational programs could use this drive for material comfort to encourage more deliberative consumption behavior.

\section{Acknowledgments}

We would like to thank the four anonymous reviewers for their diligent reading of our draft and very helpful suggestions for improving our paper.

\section{References}

Barber, B. 2007. Consumed: How markets corrupt children, infantilize adults, and swallow citizens whole. New York: W. W. Norton \& Company.

Baron, R., and D. Kenney. 1986. The moderator-mediator variable distinction in social psychological research: Conceptual, strategic, and statistical considerations. Journal of Personality and Social Psychology, 51 (6): 11731182. http://dx.doi.org/10.1037/0022-3514.51.6.1173

Belk, Russell W. 1984. Three scales to measure constructs related to materialism: Reliability, validity and relationships to measures of happiness. In Advances in consumer research, Vol.11, ed. Thomas Kinnear.

Cokely, E., and C. Kelley. 2009. Cognitive abilities and superior decision making under risk: A protocol analysis and process model evaluation. Judgment and Decision Making, 4 (1): 20-33.

Cole, L., and D. Sherrell. 1995. Comparing scales to measure compulsive buying: an exploration of their dimensionality. In Advances in consumer research, Vol. 22, ed. F. Kardes and M. Sujan, 419-427.

Faber, R. and T. O'Guinn. 1988. Compulsive consumption and credit abuse. Journal of Consumer Policy, 11: 97-109. http://dx.doi.org/10.1007/BF00411522

Faber, R. and T. O'Guinn. 1989. Classifying compulsive consumers: Advances in the development of a diagnostic tool. In Advances in consumer research, Vol.11, ed. T. Srull, 738-744. 
Fagerlin, A., B. Zikmund-Fisher, P. Ubel, A. Jankovic, H. Derry, and D. Smith. 2007. Measuring numeracy without a math test: Development of the Subjective Numeracy Scale. Medical Decision Making, 27: 672-680. http://dx.doi.org/10.1177/0272989X07304449

Gilliland, D., V. Melfi, A. Sikorskii, E. Corcoran, and E. Melfi. 2011. Quantitative literacy at Michigan State University, 2: Connection to financial literacy. Numeracy, 4 (2): Article 6. http://dx.doi.org/10.5038/19364660.4.2.6

Hine, T. 2002. I want that! How we all became shoppers. New York: HarperCollins Publishers.

Huston, S. 2010. Measuring financial literacy. The Journal of Consumer Affairs, 44 (2), 296-316. http://dx.doi.org/10.1111/j.1745-6606.2010.01170.x

James, O. 2008. The selfish capitalist: Origins of affluenza. London: Vermilion.

Kim, J., and T. Garman. 2003. Financial stress and absenteeism: An empirically derived model. Financial Counseling and Planning, 14 (1), 31-42.

Kim, J., T. Garman, and B. Sorhaindo. 2003. Relationships among credit counseling clients' financial well-being, financial behaviors, financial stressor events, and health. Financial Counseling and Planning, 14 (2), 7587.

Kline, R. 1998. Principles and Practice of Structural Equations Modeling. New York: The Guilford Press.

Koran, L., R. Faber, E. Aboujaoude, M. Large, and R. Serpe. 2006. Estimated prevalence of compulsive buying behavior in the United States. American Journal of Psychiatry, 163: 1806-1812. http://dx.doi.org/10.1176/appi.ajp.163.10.1806

Lipkus, I., and E. Peters. 2009. Understanding the role of numeracy in health: Proposed theoretical framework and practical insights. Health Educ Behav 36: 1065-1081. http://dx.doi.org/10.1177/1090198109341533

Lusardi, A., and O. Mitchell. 2007. Financial literacy and retirement planning: New evidence from the Rand American Life Panel. Michigan Retirement Research Center Working Paper 2007-157. http://www.dartmouth.edu/ alusardi/Papers/American_Life_Panel.pdf

Mills, R., H. Grasmick, C. Morgan, and D. Wenk. 1992. The effect of gender, family satisfaction, and economic strain on psychological well-being. Family Relations, 41, 440-446. http://dx.doi.org/10.2307/585588

Mirowsky, J., and C. Ross. 2003. Social causes of psychological distress, $2^{\text {nd }}$ ed. New York: Aldine de Gruyter.

Prawitz, A., T. Garman, B. Sorhaindo, B. O’Neill, J. Kim, and P. Drentea. 2006a. InCharge Financial Distress/Financial Well-Being Scale: Development, administration, and score interpretation. Financial Counseling and Planning, 17 (1): 34-50. 
Prawitz, A., T. Garman, B. Sorhaindo, B. O'Neill, J. Kim, and P. Drentea. 2006 b. The InCharge Financial Distress/Financial Well-Being Scale: Establishing validity and reliability. Proceedings of the Association for Financial Counseling and Planning Education.

Richins, M. 1994. Valuing things: The public and private meanings of possessions. Journal of Consumer Research, 21 (December): 504-521. http://dx.doi.org/10.1086/209414

Richins, M. 2004. The Material Values Scale: Measurement properties and development of a short form. Journal of Consumer Research, 31 (June): 209-219.

Richins, M., and S. Dawson. 1992. Special possessions and the expression of material values. Journal of Consumer Research, 21 (December): 522-533.

Schor, J. 1998. The overspent American: Upscaling, downshifting and the new consumer. New York: HarperCollins Publishers.

Stegman, M. 2007. Payday lending. Journal of Economic Perspectives, 21 (1): 169-190.

Zikmund-Fisher, B, D. Smith, P. Ubel, and A. Fagerlin. 2007. Validation of the Subjective Numeracy Scale: Effects of low numeracy on comprehension of risk communications and utility elicitations. Medical Decision Making, 27: 


\section{Appendix A:}

\section{Financial Behavior Scale}

Behavioral Statements ${ }^{1} \quad$ (15 items)

pawn a valuable possession

miss car payments

take out "pay day" loans

pay my bills on time

borrow to pay monthly expenses

take cash advance on credit card

my monthly bills are more than earnings

overdraft my checking account

follow a monthly budget to control spending

save for important purchases

save for unexpected expenses

invest in stocks or mutual funds

contribute to retirement plan

finance a balance my on credit card

use more than three credit cards



C $\quad .826$

C $\quad .773$

C $\quad .690$

F $\quad-.659$

C $\quad .633$

C $\quad .570$

C $\quad .483$

$\begin{array}{lll}\text { C } & .373 & -.348\end{array}$

F $\quad .881$

F $\quad .819$

$\mathrm{F} \quad .684$

$\begin{array}{ll}\text { F } & .897\end{array}$

F $\quad .877$

1. Question: "Please indicate how often you engage in the following behaviors."

(1= never , 5 = frequently)

2. Factors extracted by principle components analysis with Promax rotation.

Factor loadings below .30 are suppressed.

3. Four factors emerge with eigenvalues greater than 1. 


\title{
Appendix B: \\ Financial Quantitative Literacy Assessment
}

\author{
Correct answers are underlined.
}

Instructions: Please circle the response ( $a, b$ or $c$ ) that you believe best answers each of the following questions. Do not linger over these questions. Simply provide your best judgment. Feel free to use a calculator.

1. Suppose your annual income is $\$ 40,000$. However, income taxes take 15 percent of that. For the coming year you have budgeted the following expenses: $\$ 8,000$ for food and household items, $\$ 11,000$ for rent, $\$ 6,000$ for vacations and entertainment, $\$ 2,000$ for clothing and $\$ 3,000$ for transportation. If you stick to your budget, how much money will you be able to save this year?
a) nothing
b) $\$ 10,000$
c) 10 percent of your annual income

2. You want to purchase a television (HDTV) priced at $\$ 800$. If the sales tax is $8.5 \%$, what is the final cost to you?
a) $\$ 868.00$
b) $\$ 808.50$
c) $\$ 885.00$

3. One US Dollar exchanges for .75 Euros. An American tourist pays 20 Euros for an excellent dinner at a French restaurant. How much will this dinner cost in US Dollars?
a) less than $\$ 20$
b) between $\$ 20$ and $\$ 25$
c) more than $\$ 25$

4. Assume that you have $\$ 1,000$ to invest for a year. You invest half of your money in a savings account that earns an annual return of one percent (1\%), and you invest the other half in a safe investment that pays an annual return of five percent (5\%). Both investments compound interest annually. How much money will you have at the end of the year?
a) $\$ 1060$
b) $\$ 1050$
c) $\$ 1030$

5. Assume that you invest $\$ 1000$ at an interest rate of 5 percent, compounded annually. If you invest for three years, approximately how much money will you have at the end of that time?
a) $\$ 1050$
b) $\$ 1150$
c) $\$ 1158$

For questions 6 and 7, assume that Jack borrowed \$20,000 at an annual interest rate of 12\% (compounded monthly). Jack will repay the loan with monthly payments of $\$ 391.00$ for six years.

6. What total dollar amount will Jack pay over the term of the loan (interest \& principal)?
a) $\$ 22,346$
b) $\$ 24,692$
c) $\$ 28,152$ 
7. How much will Jack pay in interest over the term of the loan?
a) less than $\$ 6,000$
b) between $\$ 6,000$ and $\$ 10,000$
c) more than $\$ 10,000$

\section{Exhibit 1}

\begin{tabular}{|c|c|}
\hline Loan Amount & Fee for Loan $(\$)$ \\
\hline$\$ 50$ & 7.50 \\
\hline$\$ 100$ & 15.00 \\
\hline$\$ 150$ & 22.50 \\
\hline$\$ 200$ & 30.00 \\
\hline$\$ 500$ & 50.00 \\
\hline
\end{tabular}

Please refer to Exhibit 1 to answer the following three questions.

8. The interest rate on a $\$ 200$ loan is (?) the rate on a $\$ 100$ loan.
a) lower than
b) the same as
c) higher than

9. If you borrowed $\$ 100$ for four weeks (28 days), what total dollar amount (principal and interest) would you be required to repay.
a) $\$ 30$
b) $\$ 115$
c) $\$ 130$

10. Suppose you take a loan of $\$ 500$. You can renew the loan as many times as you like. After how many weeks will your total interest fees exceed the original amount of your loan?
a) less than 18 weeks
b) between 18 and 24 weeks
c) more 24 weeks 


\section{Exhibit 2}

Vehicle Depreciation: Truck vs. Car

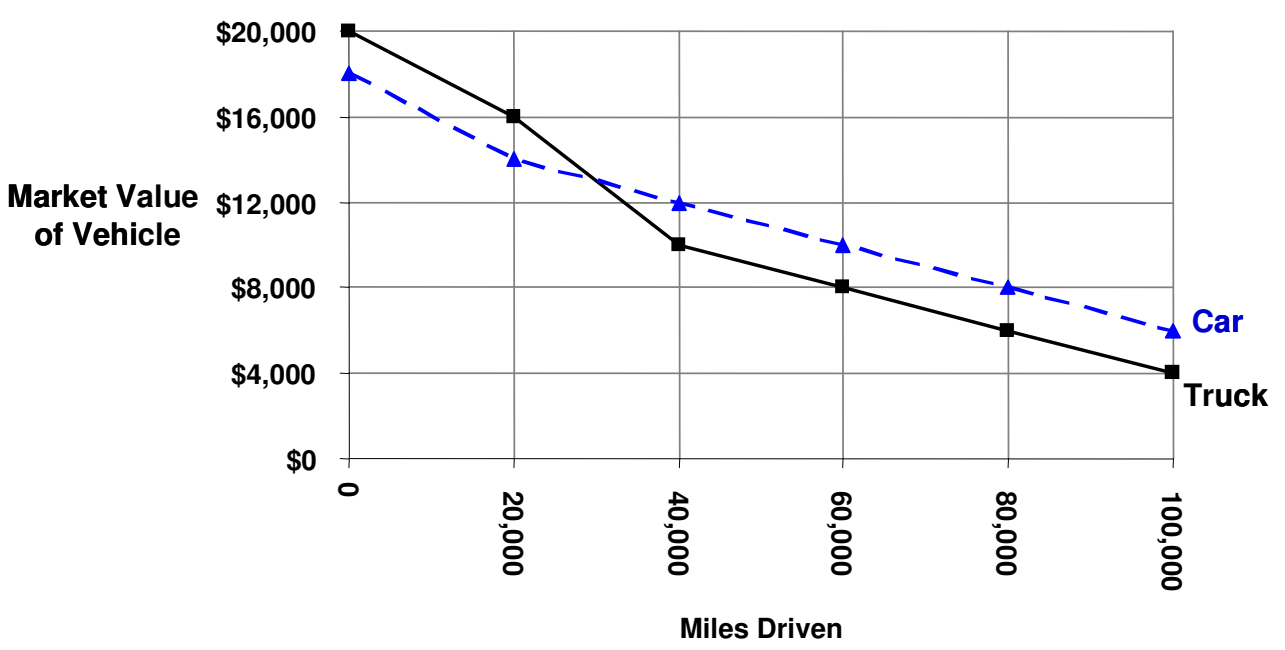

Please refer to Exhibit 2 to answer to following three questions.

A consumer plans to purchase a new vehicle, either a small pick-up truck or a compact car. The new truck is initially valued at $\$ 20,000$, while the car is worth $\$ 18,000$. Both vehicles will lose value rapidly during the first 100,000 miles driven.

11. Which vehicle loses value at a faster rate during the first 30,000 miles driven?
a) truck
b) car
c) Both lose value at about the same rate.

12. The value of the car will decline by how much $(\$)$ during the first 40,000 miles driven?
a) $\$ 8000$
b) more than $\$ 8000$
c) less than $\$ 8000$

13. After being driven 100,000 miles, the truck will be worth $\%$ of its original value.
a) $40 \%$
b) $20 \%$
c) $5 \%$ 